\title{
Maternal Depression: A Global Threat to Children's Health, Development, and Behavior and to Human Rights
}

\author{
Theodore D. Wachs, ${ }^{1}$ Maureen M. Black, ${ }^{2}$ and Patrice L. Engle ${ }^{3}$ \\ ${ }^{1}$ Purdue University, ${ }^{2}$ University of Maryland School of Medicine, and ${ }^{3}$ California Polytechnic \\ State University
}

\begin{abstract}
Depressive disorders are a common source of disability among women. In addition to the economic and human costs of maternal depression, children of depressed mothers are at risk for health, developmental, and behavioral problems. Although most of the research examining the evidence and intergenerational aspects of maternal depression has been conducted in high-income countries, recent evidence suggests that rates of maternal depression may be higher in low- and middle-income countries, where nearly $90 \%$ of the world's children live. This review examines the evidence from low- and middle-income countries that links maternal depression with children's health, development, and behavior. We present recommendations for future policies and intervention programs related to maternal depression and examine how maternal depression affects the rights of millions of children living in these countries.
\end{abstract}

KEYWORDS-maternal depression; child; low-income countries; development

Depressive disorders are common (Lepine, 2001), chronic (Pincus \& Pettit, 2001), and a principal source of disability throughout the world, especially among women (Moussavi et al., 2007). Research from high-income countries ${ }^{1}$ has documented that the economic and human costs of maternal depression are particularly insidious because they extend to the next generation, affecting children's health, development, and behavior. The symptoms that characterize maternal depression, including sadness, negative affect, loss of interest in daily activities, fatigue, difficulty thinking clearly, and bouts of withdrawal and intrusiveness may interfere with consistent, attentive, and responsive caregiving, thereby disrupting effective parenting (Paulson, Dauber, \& Leiferman, 2006). Infants are particularly vulnerable because they depend on their mothers for the primary interactions that form the basis of healthy attachment and timely acquisition of developmental skills (Coyl, Roggman, \& Newland, 2002).

We focus on the nature and consequences of maternal depression in low- and middle-income countries, where the majority of the world's children live. We examine whether the same intergenerational association between maternal depression and children's health, development, and behavior described in high-income countries exists in low- and middleincome countries. We also make recommendations for policies and intervention programs and examine how international children's rights policies are related to maternal depression. Given recent reviews on maternal depression in high-income countries (Flynn, 2005; Nylen, Moran, Franklin, \& O’Hara, 2006; Sohr-Preston \& Scaramella, 2006), our review of evidence from high-income countries is illustrative rather than systematic.

\section{MATERNAL DEPRESSION IN HIGH-INCOME COUNTRIES}

Studies from high-income countries have reported associations between maternal depression and disturbances in motherchild interactions (Lovejoy, Graczyk, O'Hare, \& Neuman, 2000), negative perceptions of infant behavior (Foreman \& 
Henshaw, 2002), and an increased likelihood of infants being perceived as temperamentally "difficult" (Edhborg, Seimyr, Lundh, \& Widstrom, 2000). Both maternal depression (Murray, Stanley, Hooper, King, \& Fiori-Cowley, 1996) and negative mother-infant interactions can be exacerbated when depressed mothers perceive their infants as temperamentally difficult (Hart, Field, \& Roitfarb, 1999). Negativity and low caregiver responsiveness may contribute to high rates of insecure attachment found among infants of depressed mothers (Martins \& Garffan, 2000). Children of depressed mothers are also at risk for slower cognitive development (Sohr-Preston \& Scaramella, 2006), low activity, difficulty interacting with unfamiliar adults, and unresponsiveness (Radke-Yarrow, 1998). Biomedical consequences include an increased risk for breastfeeding problems (Cooper, Murray, \& Stein, 1993), eating and sleep disturbances (Righetti-Veltema, Conne-Perreard, Bousquet, \& Manzano, 2002), and a reduced likelihood of receiving preventative health care (Minkovitz et al., 2005) or daily vitamin supplementation (Leiberman, 2002).

The chronic and "infectious" nature of maternal depression creates long-term risks. Prenatal maternal depression increases the risk for postpartum depression (Dennis, Janssen, \& Singer, 2004), and postpartum depression increases the risk for chronic depression (Murray, Sinclair, Cooper, Ducournau, \& Turner, 1999). Children of depressed mothers are at risk for behavioral problems throughout childhood, including symptoms of depression (Goodman \& Gotlib, 1999; Murray et al., 1999; Radke-Yarrow, 1998). Maternal depression also increases the risk of paternal depression (Goodman, 2004), which can also increase the risk of offsprings' social and behavioral problems (Ramchandani, Stein, Evans, O'Connor, and the ALSPAC Study Team, 2005).

Depression can harm mothers and children in many ways. Offspring of depressed mothers may inherit maternal genes that predispose them to increased risk for depression or developmental problems (Goodman \& Gotlib, 1999). However, maternal depression is also related to differences in children's functioning through nongenetic mechanisms (Petterson \& Albers, 2001). For example, chronically depressed mothers are less sensitive in interactions with their children than nondepressed mothers, thus undermining children's attachment security (Campbell et al., 2004). In addition, high levels of family stress may mediate the link between maternal depression and adverse childhood behavior (Dawson et al., 2003), or family stress may increase the risk of maternal depression, leading to negative mother-infant interactions, which increases the risk of insecure infant attachment (Coyl et al., 2002). Alternatively, protective factors such as higher education levels can attenuate the impact of maternal depression (van Doesum, Hosman, Riksen-Walraven, \& Hoefnagels, 2007).

In high-income countries, treatment for maternal depression commonly includes antidepressant drugs, often combined with psychological interventions (American Psychiatric Association, 2000; O’Hara, Stuart, Gorman, \& Wenzel, 2000; Verduyn,
Barrowclough, Roberts, Tarrier, \& Harrington, 2003). Providing social support can also reduce the risk of subsequent maternal depression (Dennis \& Creedy, 2004). Although maternal depression can be successfully treated, residual consequences to mother-child interactions or children's cognitive and socialemotional development often persist (Forman et al., 2007; Nylen et al., 2006). Treatment programs that include motherinfant interactions have reported gains in both the quality of mother-infant interactions and child functioning (Nylen et al., 2006; Toth, Rogosch, Manly, \& Cicchetti, 2006).

\section{MATERNAL DEPRESSION IN LOW- AND MIDDLE- INCOME COUNTRIES}

Although nearly $90 \%$ of the worlds' children live in low- and middle-income countries (United Nations Children's Fund [UNICEF], 2004), we know little about the prevalence of maternal depression (Patel, Araya, \& Bolton, 2004; Simon, Fleck, Lucas, \& Bushnell, 2004) or the consequences on children's health, development, and behavior in these countries (Rahman, Harrington, \& Bunn, 2002). However, recent evidence suggests that maternal depression is relatively common and represents a major developmental risk (Walker et al., 2007).

Prevalence and Risk Factors Associated With Maternal Depression The prevalence of maternal depression in low- and middleincome countries is estimated at $15 \%-28 \%$ in Africa and Asia (Husain, Creed, \& Tomenson, 2000), 28\%-57\% in Pakistan (Kazi et al., 2006), and 35\%-50\% in Latin America (Wolf, DeAndraca, \& Lozoff, 2002). Although genetic predisposition or neurochemical imbalances significantly contribute to the causes of depression (Dawson et al., 2003), there are other risk factors (Lesch, 2004). The relatively high prevalence of maternal depression in low- and middle-income countries may be related to women's exposure to multiple depression-related risk factors (Broadhead \& Abas, 1998), including conflict, disasters, violence, migration, and a high prevalence of HIV/AIDS (Dhanda \& Narayan, 2007; Stein et al., 2005). For example, in the relatively impoverished state of Bihar in India, only $45 \%$ of married women participate in household decisions and $58 \%$ report spousal violence (International Institute for Population Sciences, 2007).

Table 1 shows a summary of depression-related risk factors. Although poverty and economic stress are associated with maternal depression in both high-income (Murray, 1997; Petterson \& Albers, 2001) and low- and middle-income countries (Table 1), rates of poverty and economic stress are much higher in low- and middle-income countries (UNICEF, 2004). The initial consequences of poverty in low- and middleincome countries are compounded by the lost work capacity and treatment costs of maternal depression, which add to economic stress (Patel, Chisholm, Kirkwood, \& Mabey, 2007). Economic stress also may increase the risk of domestic violence, which has 
Table 1

Depression-Related Risk Factors for Women in Low- and Middle-Income Countries

\begin{tabular}{|c|c|}
\hline Risk factors & Supporting references \\
\hline Poverty or high levels of economic stress & $\begin{array}{l}\text { Ahmad and Khan (2005); Husain et al. (2000); } \\
\text { Mirza and Jenkins (2004); Patel, Kirkwood, Pednek, } \\
\text { Weiss, and Mabey (2006); Rahman and Creed (2007); } \\
\text { Rahman, Iqbal, and Harrington (2003) }\end{array}$ \\
\hline Low social support & $\begin{array}{l}\text { Kazi et al. (2006); Lee, Yip, Alexander, Leung, and } \\
\text { Chung (2004); Mirza and Jenkins (2004); Rahman and } \\
\text { Creed (2007); Rahman et al. (2003); Rodrigues, Patel, } \\
\text { Jaswal, and de Souza (2003); Tomlinson, Swartz, Cooper, } \\
\text { and Molteno (2004) }\end{array}$ \\
\hline Domestic violence & Fischbach and Herbert (1997) \\
\hline Chronic maternal illness & Moussavi et al. (2007) \\
\hline Maternal anemia & Beard et al. (2005); Corwin, Murray-Kolb, and Beard (2003) \\
\hline $\begin{array}{l}\text { Lack of awareness by primary health care workers that } \\
\text { depression is a medical-mental health problem }\end{array}$ & Kirkmayer (2001); Rodrigues et al. (2003) \\
\hline Depression not identified or diagnosed by primary health care workers & $\begin{array}{l}\text { Araya, Wynn, Leonard, and Lewis (1994); } \\
\text { Araya et al. (2001) }\end{array}$ \\
\hline $\begin{array}{l}\text { Social stigma associated with a family member being } \\
\text { diagnosed with a mental illness }\end{array}$ & Rahman et al. (1998) \\
\hline $\begin{array}{l}\text { Families with large numbers of children (four or more), especially } \\
\text { when children are below } 7 \text { years of age }\end{array}$ & $\begin{array}{l}\text { Husain et al. (2000); Rahman and Creed (2007); } \\
\text { Rahman et al. (2003) }\end{array}$ \\
\hline Having a preterm infant or an infant with low birth weight & Madu \& Roos (2006) \\
\hline Having a child with developmental disabilities & Azar and Badr (2006) \\
\hline Having an unplanned or unwanted infant & Tomlinson et al. (2004) \\
\hline Female child in a culture where there is a strong preference for male children & Ahmad and Khan (2005); Patel et al. (2002) \\
\hline $\begin{array}{l}\text { Lack of participation in family financial decisions and lack of control } \\
\text { over resources or reproductive health }\end{array}$ & Rahman et al. (2003) \\
\hline
\end{tabular}

been linked to maternal depression. Many factors that contribute to maternal depression are common in low- and middleincome countries, including maternal iron-deficiency anemia (Stoltzfus, Mullany, \& Black, 2005), large family size (UNICEF, 2004), and low birth weight (Walker et al., 2007).

As also shown in Table 1, there are culture-related risks for maternal depression. In cultures where there is a strong gender preference for boys, the birth of a girl may increase the risk of maternal depression. In other cultures, women have little control or input into family financial decisions, which can increase their risk for depression.

Maternal depression in low- and middle-income countries may also reflect the absence of protective factors that can buffer against depression. For example, although better educated women are less likely to be depressed than poorly educated women (Husain et al., 2000; Kazi et al., 2006; Mirza \& Jenkins, 2004; Patel, Rodrigues, \& DeSouza, 2002), gender gaps in secondary education are characteristic in many low- and middleincome countries (UNICEF, 2004).

\section{Consequences of Maternal Depression}

Table 2 shows that many of the adverse consequences found for children of depressed mothers in high-income countries also occur in low- and middle-income countries, including difficult temperament, behavior problems, and deficits in cognitive performance and academic achievement. Health consequences include poor physical growth and an increased risk of gastrointestinal illness. In addition, in low- and middle-income countries, maternal depression also increases the risk for paternal depression (Pinheiro et al., 2006).

Similar to reports from high-income countries, reduced responsive and stimulating child care can result in adverse psychosocial consequences for children of depressed mothers (Cooper et al., 1999; Salt, Galler, \& Ramsey, 1988). For example, maternal childrearing behaviors mediate the relation between maternal depression and insecure infant attachment in low-income families in South Africa (Tomlinson, Cooper, \& Murray, 2005). Depressed mothers are more likely to terminate weaning early due to breastfeeding problems, which may result in adverse health consequences and malnutrition. Underlying both psychosocial and biological consequences is the likelihood that symptoms of maternal depression are chronic (Rahman \& Creed, 2007).

Consistent with research from high-income countries, the risks associated with maternal depression interact in a synergistic fashion. For example, a recent investigation from rural Bangladesh demonstrated that when maternal depressive symptoms occurred in conjunction with perceptions of infant 
Table 2

Consequences to Children of Depressed Mothers Living in Low- and Middle-Income Countries

\begin{tabular}{lc}
\hline \hline Consequences & \multicolumn{1}{c}{ Supporting references } \\
\hline $\begin{array}{l}\text { Child perceived as } \\
\text { having a difficult } \\
\text { temperament }\end{array}$ & Galler, Harrison, Ramsey, \\
$\begin{array}{l}\text { Behavior problems } \\
\text { Childhood depression }\end{array}$ & Butler, and Forde (2004) \\
& Galler, Harrison, Ramsey, Forde, \\
& and Butler (2000); Patel, \\
Cognitive delay & DeSouza, and Rodrigues (2003) \\
Motor delay & Black et al. (2007); Galler et al. (2000); \\
Low academic & Patel et al. (2003) \\
achievement & Black et al. (2007) \\
Gndernutrition, stunting,, & Raller et al. (2004b); Salt et al. (1988) \\
or diarrhea & Harrington (2004); Rahman, \\
Problems in & Lovel, Bunn, Iqbal, and \\
breastfeeding & Harrington (2004); Rahman, \\
\hline \hline
\end{tabular}

irritability, infants acquired fewer cognitive, motor, and behavioral skills than when mothers had neither or only one condition (Black et al., 2007). The relation between maternal depressive symptoms, perceived infant irritability, and infant cognitive skills was partially mediated by parental responsiveness and opportunities for play in the home, suggesting that caregiving behavior is influenced by both depressive symptoms and perceptions of infant temperament.

\section{Identification Programs}

Brief screening methods have been effective in identifying women with depressive symptoms in both high-income (Arroll, Khin, \& Kerse, 2003) and low- and middle-income countries (Ahmad \& Khan, 2005; Fuggle, Glover, Khan, \& Haydon, 2002; Vega-Dienstmaier, Mazzotto, \& Campos, 2002). However, utilization of screening is low and many women with depression are not identified. In low- and middle-income countries, women are generally treated by primary health care workers who may have limited training in the recognition and treatment of depression, little awareness of the serious nature of maternal depression, a heavy patient load, and few resources (Araya et al., 2003; Wang et al., 2007). There is a critical need for frontline staff to be trained to identify mental health problems and to distinguish mental health disorders from daily stresses (Araya, Lewis, Rojas, \& Mann, 2001). Such training need not be restricted to primary health care workers. A study in rural Pakistan showed that secondary school children who received a 4-month mental health module had a better understanding of mental health and were more able to recognize depression than children who did not receive training (Rahman, Mubbashar, Gater, \& Goldberg, 1998). Benefits extended to family members who were not directly exposed to information in the module.

\section{Treatment}

Although identification of depression without effective treatment raises ethical concerns, and untreated depression is likely to become chronic, many women with depression in low- and middle-income countries receive no treatment. Antidepressant drugs used in high-income countries are effective in low- and middle-income countries (Patel, Araya, Chatterjee, et al., 2007; Rahman et al., 2002), but antidepressants are infrequently used because of the lack of psychiatrists (Patel et al., 2004), high cost of medications (Bolton et al., 2003; Saxena, Thornicroft, Knapp, \& Whiteford, 2007), and low rates of patient adherence (Kirkmayer, 2001). However, psychosocial interventions have been used successfully in low- and middle-income countries (Patel, Araya, Chatterjee, et al., 2007). Table 3 shows some examples of successful interventions that build on influences related to maternal depression or on existing health structures.

Treatment approaches based on increasing social support or on enhancing mother-infant interactions have proven effective. The cultural value of group as opposed to individual intervention (Patel et al., 2004) has led to group therapy treatments. However, there is a critical need in low- and middle-income countries for trained mental health personnel to carry out such interventions (Saxena et al., 2007), and reliance on one treatment type may be insufficient (American Psychiatric Association, 2000; Nylen et al., 2006). An appropriate model for use in low- and middle-income countries begins with alleviation of environmental stressors, follows with psychosocial interventions, and progresses to drug treatments for women who do not respond and require more intensive intervention (Araya et al., 2003).

Other cost-effective approaches rooted in child development research have the potential to reduce maternal depression. Interventions designed to promote school attendance by females may reduce the risk of both maternal depression and the intergenerational transmission of depression and poverty. Alternatively, findings from high-income countries indicate that infant massage may help mothers recognize their infant's signals of pleasure and discomfort and reduce the negative consequences of depression for both mothers and infants (Glover, Onozama, \& Hodgkinson, 2002). Future research in low-income countries should use mother-infant interactions as a focus of treatment.

\section{MATERNAL DEPRESSION AND CHILDREN'S RIGHTS}

From a global perspective, maternal depression compromises families' economic productivity, children's development, and principles of social justice. A recent series of articles highlighted the lack of attention to mental health in the global health 
Table 3

Psychosocial Approaches to Treatment of Maternal Depression Validated in Low- and Middle-Income Countries

\begin{tabular}{|c|c|}
\hline Strategy & Evidence \\
\hline $\begin{array}{l}\text { Social support for depressed mothers } \\
\text { or mothers at risk of depression }\end{array}$ & $\begin{array}{l}\text { Taiwan: Four weekly support groups led by nurses for depressed mothers of 6- to 10-month-old } \\
\text { infants led to significant reduction in maternal depressive symptoms (Chen, Tseng, Chou, \& } \\
\text { Wang, 2000). Pakistan: Community women were given brief training in providing weekly } \\
\text { social support based counseling for } 8 \text { weeks to depressed women. Treatment resulted in } \\
\text { a significant reduction in depressive symptoms (Ali et al., 2003) }\end{array}$ \\
\hline Group therapy & $\begin{array}{l}\text { Uganda: Time-limited group therapy focused on promoting interpersonal relations (a strong cultural } \\
\text { value in Uganda), using group leaders who had received } 2 \text { weeks of training, led to a significant } \\
\text { reduction in depressive symptoms (Bolton et al., 2003) }\end{array}$ \\
\hline Use of existing health mechanisms & $\begin{array}{l}\text { Jamaica: Community health workers visited homes of mothers weekly for a year. Parenting issues } \\
\text { were discussed, and mothers were shown play activities for their children. Mothers who had } \\
\text { at least } 25 \text { visits were significantly less likely to develop depressive symptoms than mothers } \\
\text { with fewer than } 25 \text { visits (Baker-Henningham, Powell, Walker, \& Grantham-McGregor, 2005) }\end{array}$ \\
\hline Enhance mother-infant interactions & $\begin{array}{l}\text { South Africa: In a sample of women at risk for depression, enhancing mother-infant interactions } \\
\text { led to improvements in both mother-infant interactions and infant physical growth } \\
\text { (Cooper et al., 2002) }\end{array}$ \\
\hline
\end{tabular}

agenda (Prince et al., 2007; Saxena et al., 2007) and emphasized the importance of women's mental health for children's development (Gill, Pande, \& Malhotra, 2007). However, the public health commitment to mental health has been minimal in many low- and middle-income countries (Patel, Saraceno, \& Kleinman, 2006). Few health programs include treatment for depression despite its high disease burden (Lopez, Mathers, Ezzati, Jamison, \& Murrary, 2006). Arguments for the prevention and treatment of maternal depression extend beyond child development and economic improvements (Gill et al., 2007; Mirza \& Jenkins, 2004 ) to include moral and rights-based agreements (Dhanda \& Narayan, 2007; Patel, Saraceno, et al., 2006). Policies and programs that reduce maternal depression will both improve women's functioning and children's health, development, and behavior, and protect women's and children's rights.

Among the strategies to convince governments to take more action are conventions such as the United Nations 1989 Convention on the Rights of the Child (CRC; Convention on the Rights of the Child [CRPD], 2002) and its 2006 Convention on the Rights of Persons With Disabilities (CRPD; 2006). The CRC, the most widely ratified convention of the United Nations (ratified by all countries except the United States), lays out actions that "States Parties" or governments must take to ensure children's rights. Four main principles are the right to survival and development, the universality of rights, the indivisibility of rights, and the best interests of the child (CRC, 2002). Conventions also define who is responsible for fulfilling rights. For example, although governments are responsible ("duty bearers") for ensuring that families have the livelihood and support needed to fulfill their responsibilities, families are also responsible.

Several of the 41 articles in the CRC are relevant to maternal depression. Article 2 states that children should not face discrimination on the basis of parents' disability, including mental illness, and that governments should actively support parental childrearing efforts and promote facilities and services focusing on the care of children. Article 27 states that governments recognize "the right of every child to a standard of living adequate for the child's physical, mental, spiritual, moral and social development" and assist parents in ensuring this right (CRC, 2002).

The CRDP, signed after a decade of advocacy, includes maternal depression as a disability (Article 1). It includes protection for individuals (Dhanda \& Narayan, 2007) and requires governments to provide both medical and social support. For example, Article 6 notes that "women and girls with disabilities are subject to multiple discrimination, and in this regard States Parties [governments] shall take measures to ensure the full and equal enjoyment by them of all human rights and fundamental freedoms" (CRPD, 2006). The CRPD also challenges stereotypes about mental illness and argues for creative strategies including self-help groups, occupational training, lifeskills education, parenting skills, and local healing traditions (Dhanda \& Narayan, 2007). As written, the Conventions provide powerful tools for increasing government support to reduce maternal depression.

To increase policy makers' awareness of maternal depression, a U.N. Fund for Population Activities (UNFPA) and World Health Organization (WHO) International expert group developed a Consensus Statement on the interface between maternal mental health and child health and development in low-income countries. The Statement made three recommendations that addressed mental health as part of an overall program to improve maternal and child health: (a) reduce the factors that lead to maternal depression, (b) promote maternal and child health and development, and (c) increase availability of lowcost evidence-based interventions for maternal mental health problems. The Consensus Statement concludes that "political 
will, concerted action by global stakeholders and resources are needed now to integrate maternal mental health in endeavors to achieve the Millennium Development Goals" (WHO-UNFPA, 2007 , p. 3). Implementing the recommendations from the Statement requires a comprehensive, adequately funded approach to mental health, including the incorporation of mental health into existing health systems, with early detection and medication for the most severe cases; research on effective interventions such as social support, development of a legal and policy framework, stigma reduction, and capacity building.

\section{SUMMARY}

The prevention and treatment of maternal depression in lowand middle-income countries require continued advocacy. Mental health professionals in high-income countries are a valuable resource. They can advocate for mental health services within their own health systems and also address issues on the global mental health agenda. Investment in the prevention and treatment of maternal depression can interrupt the intergenerational cycle of depressive symptoms, thereby protecting both mothers and their children. Programs and policies are needed to develop effective and accessible identification, treatment, and prevention strategies for low- and middle-income countries; to reduce the prevalence of depressive symptoms; and to help families provide enriching opportunities and responsive interactions for mothers and children. Global policies and programs designed to reduce maternal depression are a critical component of protecting women's and children's rights.

\section{REFERENCES}

Ahmad, I., \& Khan, M. (2005). Risk factors associated with post-natal depression in Pakistani women. Pakistan Journal of Social and Clinical Psychology, 3, 41-50.

Ali, B., Rahbar, M., Naeem, S., Gul, A., Mubeen, S., \& Iqbal, A. (2003). The effectiveness of counseling on anxiety and depression by minimally trained counselors: A randomized control trial. American Journal of Psychotherapy, 57, 324-336.

American Psychiatric Association. (2000). Practice guideline for the treatment of patients with major depressive disorder (revision). American Journal of Psychiatry, 157(Suppl. 4), 1-45.

Araya, R., Lewis, G., Rojas, G., \& Mann, A. (2001). "Patient knows best"-detection of common mental disorders in Santiago, Chile: Cross sectional study. British Medical Journal, 322, 79-80.

Araya, R., Rojas, G., Fritsch, R., Gaete, J., Rojas, M., Simon, G., et al. (2003). Treating depression in primary care in low-income women in Santiago, Chile: A randomized controlled trial. Lancet, 361, 995-1000.

Araya, R., Wynn, R., Leonard, R., \& Lewis, G. (1994). Psychiatric morbidity in primary health care in Santiago, Chile: Preliminary findings. British Journal of Psychiatry, 165, 530-533.
Arroll, B., Khin, N., \& Kerse, N. (2003). Screening for depression in primary care with two verbally asked questions: Cross sectional study. British Medical Journal, 327, 1144-1146.

Azar, M., \& Badr, L. (2006). The adaptation of mothers of children with intellectual disability in Lebanon. Journal of Transcultural Nursing, 17, 375-380.

Baker-Henningham, H., Powell, C., Walker, S., \& Grantham-McGregor, S. (2005). The effect of early stimulation on maternal depression: A cluster randomized controlled trial. Archives of Disease in Childhood, 90, 1230-1234.

Beard, J., Handricks, M., Perez, E., Murray-Kolb, L., Berg, A., Vernon-Feagans, L., et al. (2005). Maternal iron deficiency anemia affects postpartum emotions and cognition. Journal of Nutrition, 135, 267-272.

Black, M., Baqui, A., Zaman K., McNary, S., Le, K., Arifeeen, S., et al. (2007). Depressive symptoms among rural Bangladeshi mothers: Implications for infant development. Journal of Child Psychology and Psychiatry, 48, 764-772.

Bolton, P., Bass, J., Neugebauer, R., Verdeli, H., Clougherty, K., Wickramaratne, P., et al. (2003). Group interpersonal psychotherapy for depression in rural Uganda. Journal of the American Medical Association, 289, 3117-3124.

Broadhead, J., \& Abas, M. (1998). Life events, difficulties and depression among women in an urban setting in Zimbabwe. Psychological Medicine, 28, 29-38.

Campbell, S., Brownell, C., Hungerford, A., Spieker, S., Mohan, R., \& Blessing, J. (2004). The course of maternal depressive symptoms and maternal sensitivity as predictors of attachment security at 36 months. Development and Psychopathology, 16, 231-252.

Chen, C., Tseng, Y., Chou, F., \& Wang, S. (2000). Effects of support group intervention in postnatally distressed women: A controlled study in Taiwan. Journal of Psychosomatic Research, 49, 395-399.

Cooper, P., Landman, M., Tomlinson, M., Molteno, C., Swartz, L., \& Murray, L. (2002). Impact of a mother-infant intervention in an indigent peri-urban South African context. British Medical Journal, 180, 76-81.

Cooper, P., Murray, L., \& Stein, A. (1993). Psychosocial factors associated with the early termination of breast-feeding. Journal of Psychosomatic Research, 37, 171-176.

Cooper, P., Tomlinson, M., Swartz, L., Woolgar, M., Murray, L., \& Molteno, C. (1999). Post-partum depression and the motherinfant relationship in a South African peri-urban settlement. British Journal of Psychiatry, 175, 554-558.

Corwin, E., Murray-Kolb, L., \& Beard, J. (2003). Low hemoglobin level is a risk factor for postpartum depression. Journal of Nutrition, 133, 4139-4142.

Convention on the Rights of the Child. (2002). A world fit for children. New York: UNICEF.

Convention on the Rights of Persons With Disabilities. (2006). Office of the United Nations High Commissioner for Human Rights Web site. Available at http://www2.ohchr.org/english/law/disabil ities-convention.htm

Coyl, D., Roggman, L., \& Newland, L. (2002). Stress, maternal depression and negative mother-infant interactions in relation to infant attachment. Infant Mental Health Journal, 23, $145-163$.

Dawson, G., Ashman, S., Panagiotides, H., Hessl, D., Self, J., Yamada, E., et al. (2003). Preschool outcomes of children of depressed mothers: Role of maternal behavior, contextual risk 
and children's brain activity. Child Development, 74, 1158-1175.

Dennis, C., \& Creedy, D. (2004). Psychosocial and psychological interventions for preventing postpartum depression. Cochrane Database of Systematic Reviews, 4, CD001134, pub2.

Dennis, C., Janssen, P., \& Singer, J. (2004). Identifying women atrisk for postpartum depression in the immediate postpartum period. Acta Psychiatrica Scandinavica, 110, 338-346.

Dhanda, A., \& Narayan, T. (2007). Mental health and human rights. Lancet, 370, 1197-1198.

Edhborg, M., Seimyr, L., Lundh, W., \& Widstrom, A. (2000). Fussy child-difficult parenthood? Comparisons between families with a "depressed" mother and non-depressed mother 2 months postpartum. Journal of Reproductive and Infant Psychology, 18, 226-238.

Falceto, O., Giugliani, E., \& Fernandes, C. (2004). Influence of parental mental health on early termination of breast-feeding: A case-control study. Journal of the American Board of Family Practice, 17, 173-183.

Fischbach, R. L., \& Herbert, B. (1997). Domestic violence and mental health: Correlates and conundrums within and across cultures. Social Science \& Medicine, 45, 1161-1176.

Flynn, H. (2005). Epidemiology and phenomenology of postpartum mood disorders. Psychiatric Annals, 35, 544-551.

Foreman, D., \& Henshaw, C. (2002). Objectivity and subjectivity in postnatally depressed mothers'perceptions of their infants. Child Psychiatry and Human Development, 32, 263-275.

Forman, D., O'Hara, M., Stuart, S., Gorman, L., Larsen, K., \& Coy, K. (2007). Effective treatment for postpartum depression is not sufficient to improve the developing mother-child relationship. Development and Psychopathology, 19, 585-602.

Fuggle, P., Glover, L., Khan, F., \& Haydon, K. (2002). Screening for postnatal depression in Bengali women: Preliminary observations from using a translated version of the Edinburgh Postnatal Depression Scale (EPDS). Journal of Reproductive and Infant Psychology, 20, 71-82.

Galler, J., Harrison, R., Ramsey, F., Butler, S., \& Forde, V. (2004). Postpartum maternal mood, feeding practices, and infant temperament in Barbados. Infant Behavior and Development, 27, $267-287$.

Galler, J., Harrison, R., Ramsey, F., Chawla, S., \& Taylor, J. (2006). Postpartum feeding attitudes, maternal depression, and breastfeeding in Barbados. Infant Behavior \& Development, 29, 189-203.

Galler, J., Harrison, R., Ramsey, F., Forde, V., \& Butler, S. C. (2000). Maternal depressive symptoms affect infant cognitive development in Barbados. Journal of Child Psychology and Psychiatry, $41,747-757$.

Galler, J., Ramsey, F., Harrison, R., Taylor, J., Cumberbatch, G., \& Forde, V. (2004). Postpartum maternal moods and infant size predict performance on a national high school entrance examination. Journal of Child Psychology and Psychiatry, 45, 1064-1075.

Gill, K., Pande, R., \& Malhotra, A. (2007). Women deliver for development. The Lancet, 370, 1347-1357.

Glover, V., Onozama, K., \& Hodgkinson, A. (2002). Benefits of infant massage for mothers with postnatal depression. Seminars in Neonatology, 7, 495-500.

Goodman, J. (2004). Postpartum depression beyond the early postpartum period. Journal of Obstetric, Gynecologic and Neonatal Nursing, 33, 410-420.
Goodman, S., \& Gotlib I. (1999). Risk for psychopathology in the children of depressed mothers: A developmental model for understanding mechanisms of transmission. Psychological Review, 106, 458-490.

Hart, S., Field, T., \& Roitfarb, M. (1999). Depressed mothers' assessments of their neonates' behaviors. Infant Mental Health Journal, 20, 200-210.

Husain, N., Creed, F., \& Tomenson, B. (2000). Depression and social stress in Pakistan. Psychological Medicine, 30, 395-402.

International Institute for Population Sciences. (2007). National Family Health Survey-3. Mumbai, India: Author.

Josefsson, A., \& Sydsjo, G. (2007). A follow-up study of postpartum depressed women: Recurrent maternal depressive symptoms and child behavior after four years. Archives of Women's Mental Health, 10, 141-145.

Kazi, A., Fatmi, Z., Hatcher, J., Kadir, M., Niaz, U., \& Wasserman, G. (2006). Social environment and depression among pregnant women in urban areas of Pakistan: Importance of social relations. Social Science \& Medicine, 6, 1466-1476.

Kirkmayer, L. (2001). Cultural variations in the clinical presentation of depression and anxiety. Journal of Clinical Psychiatry, 62(Suppl. 13), 22-28.

Lee, D., Yip, T., Alexander, S., Leung, T., \& Chung, T. (2004). Ethnoepidemiology of postnatal depression: Prospective multivariate study of sociocultural risk factors in a Chinese population in Hong Kong. British Journal of Psychiatry, 184, 34-40.

Leiberman, J. (2002). The effect of maternal depressive symptomatology on maternal behaviors associated with child health. Health Education \& Behavior, 29, 596-607.

Lepine, J. (2001). Epidemiology, burden, and disability in depression and anxiety. Journal of Clinical Psychiatry, 62, 4-10.

Lesch, K. (2004). Gene-environment interaction and the genetics of depression. Journal of Psychiatry and Neuroscience, 29(3), 174-184.

Lopez, A., Mathers, C., Ezzati, M., Jamison, D., \& Murrary, C. (2006). Global burden of disease and risk factors. Washington, DC: Oxford University Press and the World Bank.

Lovejoy, M., Graczyk, P., O'Hare, E., \& Neuman, G. (2000). Maternal depression and parenting behavior: A meta-analytic review. Clinical Psychological Review, 20, 561-592.

Madu, S., \& Roos, J. (2006). Depression among mothers with preterm infants and their stress-coping strategies. Social Behavior and Personality, 34, 877-890.

Martins, C., \& Garffan, E. (2000). Effects of early maternal depression on patterns of infant-mother attachment: A metaanalytic investigation. Journal of Child Psychology \& Psychiatry, $41,737-746$.

Minkovitz, C., Strobino, S., Scharfstein, D., Hou, W., Miller, T., Mistry, K., et al. (2005). Maternal depressive symptoms and children's receipt of health care in the first 3 years of life. Pediatrics, 115, 306-314.

Mirza, I., \& Jenkins, R. (2004). Risk factors, prevalence and treatment of anxiety and depressive disorders in Pakistan: Systematic review. British Medical Journal, 328, 794-797.

Moussavi, S., Chatterji, S., Verdes, E., Tandon, A., Patel, V., \& Ustun, B. (2007). Depression, chronic diseases, and decrements in health: Results from the World Health Surveys. Lancet, 370, 851-858.

Murray, L. (1997). Postpartum depression and child development. Psychological Medicine, 27, 253-260. 
Murray, L., Sinclair, D., Cooper, P., Ducournau, P., \& Turner, P. (1999). The socioemotional development of 5-year-old children of postnatally depressed mothers. Journal of Child Psychology \& Psychiatry, 40, 1259-1271.

Murray, L., Stanley, C., Hooper, R., King, F., \& Fiori-Cowley 1996). The role of infant factors in postnatal depression and motherinfant interactions. Developmental Medicine and Child Neurology, 38, 109-119.

Nylen, K., Moran, T., Franklin, C., \& O’Hara, M. (2006). Maternal depression: A review of relevant treatment approaches for mothers and infants. Infant Mental Health Journal, 27, 327-343.

O'Hara, M., Stuart, S., Gorman, L., \& Wenzel, A. (2000). Efficacy of interpersonal psychotherapy for postpartum depression. Archives of General Psychiatry, 57, 1039-1045.

Patel, V., Araya, R., \& Bolton, P. (2004). Treating depression in the developing world. Tropical Medicine and International Health, 9, 539-541.

Patel, V., Araya, R., Chatterjee, S., Chisholm, D., Cohen, A., De Silva, M., et al. (2007). Treatment and prevention of mental disorders in low-income and middle-income countries. Lancet, 370, 991-1005.

Patel, V., Chisholm, D., Kirkwood, B., \& Mabey, D. (2007). Prioritizing health problems in women in developing countries: Comparing the financial burden of reproductive tract infections, anaemia and depressive disorders in a community survey in India. Tropical Medicine \& International Health, 12, 130-139.

Patel, V., DeSouza, N., \& Rodrigues, M. (2003). Postnatal depression and infant growth and development in low-income countries: A cohort study from Goa, India. Archives of Disease in Childhood, 88, 34-37.

Patel, V., Kirkwood, B., Pednek, S., Weiss, H., \& Mabey, D. (2006). Risk factors for common mental disorders. British Journal of Psychiatry, 189, 547-555.

Patel, V., Rodrigues, M., \& DeSouza, N. (2002). Gender, poverty, and postnatal depression: A study of mothers in Goa, India. American Journal of Psychiatry, 159, 43-47.

Patel, V., Saraceno, B., \& Kleinman, A. (2006). Beyond evidence: The moral case for international mental health. American Journal of Psychiatry, 163, 1312-1314.

Paulson, J., Dauber, S., \& Leiferman, J. (2006). Individual and combined effects of postpartum depression in mothers and fathers on parenting behavior. Pediatrics, 118, 659-668.

Petterson, S., \& Albers, A. (2001). Effects of poverty and maternal depression on early child development. Child Development, 72, 1794-1813.

Pincus, H., \& Pettit, A. (2001). The societal costs of chronic major depression. Journal of Clinical Psychiatry, 62, 5-9.

Pinheiro, R., Magalhaes, P., Horta, B., Pinheiro, K., da Silva, \& Pinto, R. (2006). Is paternal postpartum depression associated with maternal postpartum depression? Population-based study in Brazil. Acta Psychiatrica Scandinavica, 113, 230-232.

Prince, M., Patel, V., Saxena, S., Maj, M., Maselko, J., Phillips, M., et al. (2007). No health without mental health. Lancet, 370, 359-387.

Radke-Yarrow, M. (1998). Children of depressed mothers: From early childhood to maturity. New York: Cambridge University Press.

Rahman, A., Bunn, J., Lovel, H., \& Creed, F. (2007). Maternal depression increases infant risk of diarrhoeal illness: A cohort study. Archives of Disease in Childhood, 92, 24-28.

Rahman, A., \& Creed, F. (2007). Outcome of prenatal depression and risk factors associated with persistence in the first postnatal year: Prospective study from Rawalpindi, Pakistan. Journal of Affective Disorders, 100, 115-121.

Rahman, A., Harrington, R., \& Bunn, J. (2002). Can maternal depression increase infant risk of illness and growth impairment in developing countries? Child Care, Health and Development, $28,51-56$.

Rahman, A., Iqbal, Z., Bunn, J., Lovel, H., \& Harrington, R. (2004). Impact of maternal depression on infant nutritional status and illness. Archives of General Psychiatry, 61, 946-952.

Rahman, A., Iqbal, Z., \& Harrington, R. (2003). Life events, social support and depression in childbirth: Perspectives from a rural community in the developing world. Psychological Medicine, 33 , 1161-1167.

Rahman, A., Lovel, H., Bunn, J., Iqbal, Z., \& Harrington, R. (2004). Mothers' mental health and infant growth: A case-control study from Rawalpindi, Pakistan. Child Care, Health and Development, 30, 21-27.

Rahman, A., Mubbashar, M., Gater, R., \& Goldberg, D. (1998). Randomized trial of impact of school mental-health programme in rural Rawalpindi Pakistan. Lancet, 352, 1022-1025.

Ramchandani, P., Stein, A., Evans, J., O'Connor, T., \& the ALSPAC study team (2005). Paternal depression in the postnatal period and child development: A prospective population study. Lancet, 365, 2201-2205

Righetti-Veltema, M., Conne-Perreard, E., Bousquet, A., \& Manzano, J. (2002). Postpartum depression and mother-infant relationship at 3 months old. Journal of Affective Disorders, 70, 291-306.

Rodrigues, M., Patel, V., Jaswal, S., \& de Souza, N. (2003). Listening to mothers: Qualitative studies on motherhood and depression from Goa, India. Social Science \& Medicine, 5, 1797-1806.

Salt, P., Galler, J., \& Ramsey, F. (1988). The influence of early malnutrition on subsequent behavioral development. VII. The effects of maternal depressive symptoms. Developmental and Behavioral Pediatrics, 9, 1-5.

Saxena, S., Thornicroft, G., Knapp, M., \& Whiteford, H. (2007). Resources for mental health: Scarcity, inequity and inefficiency. Lancet, 370, 878-889.

Simon, G., Fleck, M., Lucas, R., \& Bushnell, D. (2004). Prevalence and predictors of depression treatment in an international primary care study. American Journal of Psychiatry, 161, 1626-1634.

Sohr-Preston, S., \& Scaramella, L. (2006). Implications of timing of maternal depressive symptoms for early cognitive and language development. Clinical Child and Family Psychology Review, 9, 65-83.

Stein, A., Krebs, G., Richter, L., Tomkins, A., Rochat, T., \& Bennish, M. (2005). Babies of a pandemic: Infant development and maternal HIV. Archives of Disease in Childhood, 90, 116-118.

Stoltzfus, R., Mullany, L., \& Black, R. (2005). Iron deficiency anemia. In World Health Organization (Ed.), Comparative quantification of health risks: Global and regional burden of disease attributable to selected major risk factors (Vol. 1, pp. 163-209). Geneva, Switzerland: World Health Organization.

Tomlinson, M., Cooper, P., \& Murray, L. (2005). The mother-infant relationship and infant attachment in a South African peri-urban settlement. Child Development, 76, 1044-1054.

Tomlinson, M., Swartz, L., Cooper, P., \& Molteno, C. (2004). Social factors and postpartum depression in Khayelitsha, Cape Town. South African Journal of Psychology, 34, 409-420.

Toth, S., Rogosch, F., Manly, J., \& Cicchetti, D. (2006). The efficacy of toddler-parent psychotherapy to reorganize attachment in the 
young offspring of mothers with major depressive disorder. Journal of Consulting and Clinical Psychology, 74, 1006-1016.

United Nations Children's Fund. (2004). The state of the world's children-2005. New York: Author.

van Doesum, K., Hosman, C., Riksen-Walraven, J., \& Hoefnagels, C. (2007). Correlates of depressed mothers sensitivity towards their infants: The role of maternal, child and contextual characteristics. Journal of the American Academy of Child and Adolescent Psychiatry, 46, 747-752.

Vega-Dienstmaier, J., Mazzotto, S., \& Campos, S. (2002). Validation of a Spanish version of the Edinburgh Postnatal Depression Scale. Actas Espanolas de Psiquiatria, 30, 106-111.

Verduyn, C., Barrowclough, C., Roberts, J., Tarrier, N., \& Harrington, R. (2003). Maternal depression and child behaviour problems: Randomized placebo-controlled trial of a cognitive behavioural group intervention. British Journal of Psychiatry, 183, 342-348.
Walker, S., Wachs, T. D., Meeks-Gardner, J., Lozoff, B., Wasserman, G., Pollitt, E., et al. (2007). Child development in developing countries 2: Risk factors for adverse outcomes in developing countries. Lancet, 369, 145-157.

Wang, P., Aguilar-Gaxiola, S., Alonso, J., Angermeyer, M., Borges, G., Bromet, E., et al. (2007). Use of mental health services for anxiety, mood, and substance disorders in 17 countries in the WHO world mental health surveys. Lancet, 370, 841-850.

World Health Organization-U.N. Fund for Population Activities. (2007). UNFPA-WHO consensus statement on maternal mental health and child survival/health/development in resource-constrained settings for achieving the millennium development goals. Geneva, Switzerland: WHO.

Wolf, A., DeAndraca, I., \& Lozoff, B. (2002). Maternal depression in three Latin American samples. Social Psychiatry and Psychiatric Epidemiology, 37, 169-176. 